\title{
A Heuristic Model for Tasks Scheduling in Heterogeneous Distributed Real Time System under Fuzzy Environment
}

\author{
Harendra Kumar \\ Department of Mathematics and Statistics \\ Gurkula Kangari University, Hardwar-249404, Uttarakhand (India)
}

\begin{abstract}
The development of distributed real time system (DRTS) has lead to there use in several applications including information processing, fluid flow, weather modeling, database systems, real-time high-speed simulation of dynamical systems, and image processing. Reliability analysis of these processing elements and communication links is one of the important parameter to get the system efficiency. We can improve the system performance (i.e. system cost, system reliability and processor utilization etc.) by scheduling the tasks to the processors properly in DRTS. In this paper, a new tasks allocation model has been developed with fuzzy execution times $\tilde{e}_{i, j}$ and fuzzy inter tasks communication times $\tilde{c}_{i, j}$. The times has been defuzzified into crisp one by using Robust Ranking Method [RRM], Centre of Maxima Method [CoM] and Weight of Center of Area Method [CoA].The effect of inter processor distances on the tasks allocation has been considered while developing the model. Numerical examples show that the model presented in this paper is suitable for arbitrary number of processors with random program structure and more realistic and general in nature.
\end{abstract}

\section{Keywords}

Distributed real time systems, Fuzzy execution times, Fuzzy inter tasks communication times, Reliability.

\section{INTRODUCTION}

A distributed real time system is a computing platform where hardware or software components located at networked computers communicate and coordinate their actions only by passing messages. It enables users to access services and executes applications over a heterogeneous collection of computers and networks. In a DRTS the execution of a program may be distributed among several computing elements to reduce the overall system cost by taking advantage of heterogeneous computational capabilities and other resources within the system. Reliability is defined in terms of the time interval in contrast to an instance in time defined in availability. A highly reliable system is one that will continue working for a long period of time. The often advocated advantage of the DRTS, in comparison to the centralized system, is the reliability due to the existence of multiple resources. However, only the multiple instances of resources cannot increase the reliability of the DRTS, rather the various processes of the distributed operating system (viz. memory manager, task scheduler etc.) must be designed properly to increase the reliability by extracting the characteristic features of the DRTS.

The module allocation in a distributed processing system finds extensive application in the faculties where large amount of data is to be processed in a short period of time or where real time computations are required. The main incentives for choosing DRTS are higher throughput, improved availability and better access to a widely communicated web of information. The increased commercialization of communication systems means that ensuring system reliability is of critical importance inherently. DRTS is more complex, therefore it is very difficult to predict the performance of DRTS. Mathematical modelling is the tool which can play an important role to predict the performance of DRTS. In order to make best use of the resources, it becomes essential to maximize the overall throughput by allocating the tasks to processors in such a way that the allocated load on all the processors should be balanced and to minimize the inter tasks communication by assigning tasks to same processor as much as possible. Which are both contrary to each other as an increase in the number of processors may actually decrease the total throughput of the system. This degradation effect is known as saturation effect, which occurs due to heavy communication traffic induced by data transfers between tasks that reside on separate processors. An allocation policy can be static or dynamic, depending upon the time at which the allocation decisions are made. In static allocation once a task is assigned to a processor, it remains there statically during the execution of a distributed program. Many approaches have been reported for solving the Static tasks assignment problem in a DRTS [1-7]. While in dynamic allocation a module can be reassigned during program execution [8-11]. Donight et al [12] has determined the level of reliability of components with expending low cost. X. Kong et al [13], proposed an efficient dynamic task scheduling scheme for virtualized data centres. A model for allocating the tasks to processors in heterogeneous distributed computing systems with the goal of maximizing the system reliability has been developed in [14]. Kumar et al. [15] has developed a task allocation problem using fuzzy execution and fuzzy communication times. Recently V.Sriramdas et al [16] developed a tasks allocation model treating allocation factors as fuzzy numbers.

This paper deals with the tasks allocation problem having multiple objectives such as: minimization of system cost, maximization of system reliability and load balancing for proper utilization of the processor's capacity. The rest paper is organized as follows. Tasks allocation problem with notations, definitions and assumptions used are defined first in section 2. In section 3, tasks allocation model has been discussed. The Section 4 shows the experimental results and section 5 concludes the paper.

\section{THE PROBLEM}

An allocation of tasks to processors is defined by a function, A from the set $\mathrm{T}$ of tasks to the set $\mathrm{P}$ of processors such that:

$A: T \rightarrow P$, where $A(i)=j$ if task $t_{i}$ is assigned to processor $\mathrm{p}_{\mathrm{j}}, 1 \leq \mathrm{i} \leq \mathrm{m}, 1 \leq \mathrm{j} \leq \mathrm{n}$. 
Each processor has local memory only and do not share any global memory. The fuzzy execution times (FET), $\tilde{e}_{i, j}$ of the tasks on the processors is taken in the form of matrix named as fuzzy execution time matrix (FETM), FETM $=\left[\tilde{e}_{i, j}\right]$ of order $\mathrm{m} \times \mathrm{n}$. The fuzzy inter-tasks communication times (FITCT), $\tilde{c}_{i, j}$ is taken in the form of a symmetric matrix named as fuzzy inter task communication time matrix (FITCM), FITCTM $=\left[\tilde{c}_{i, j}\right]$ of order m. In this paper times $\tilde{e}_{i, j}$ and $\tilde{c}_{i, j}$ have been considered to be triangular and trapezoidal numbers. In general the objective of this paper is to find an optimal allocation $\mathrm{A}_{\mathrm{O}}$, which minimize the response time of the program and optimize the system reliability by properly mapping the modules to the processors. In order to make the best use of the resources in a distributed computing system we would like to distribute the load on each processor in such a way that allocated load on the processors are balanced. The following notations, terms and assumptions will be used throughout the text.

\subsection{Notations:}

\begin{tabular}{|c|c|}
\hline $\mathrm{P}:$ & $\begin{array}{l}\left\{\mathrm{p}_{1}, \mathrm{p}_{2}, \cdot \cdot, \mathrm{p}_{\mathrm{n}}\right\} \text { is the set of } \mathrm{n} \text { - } \\
\text { heterogeneous processors }\end{array}$ \\
\hline $\mathrm{T}:$ & $\left\{\mathrm{t}_{1}, \mathrm{t}_{2}, \ldots, \mathrm{t}_{\mathrm{m}}\right\}$ is the set of $\mathrm{m}$-tasks \\
\hline$\tilde{e}_{i, j}:$ & $\begin{array}{l}\text { Fuzzy execution time (FET) for the task } \\
t_{i} \text {, running on processor } p_{j}\end{array}$ \\
\hline$\tilde{c}_{i, j}:$ & $\begin{array}{l}\text { Fuzzy inter-task communication time } \\
\text { (FITCT) between } t_{i} \text { and } t_{j}\end{array}$ \\
\hline $\mathrm{FETM}=\left[\tilde{e}_{i, j}\right]:$ & Fuzzy execution time matrix \\
\hline $\operatorname{FITCTM}=\left[\tilde{c}_{i, j}\right]:$ & $\begin{array}{l}\text { Fuzzy inter-task communication time } \\
\text { matrix }\end{array}$ \\
\hline$\lambda_{\mathrm{k}}:$ & Failure rate of $\mathrm{k}^{\text {th }}$ processor \\
\hline$\mu_{\mathrm{kb}}:$ & $\begin{array}{l}\text { Failure rate of communication link (or } \\
\text { path) } l_{k b} \text { between two processors } p_{k} \text { and } \\
p_{b}\end{array}$ \\
\hline $\mathrm{CLFRM}=\left[\mu_{\mathrm{kb}}\right]:$ & Communication link failure rate matrix \\
\hline $\mathrm{w}_{\mathrm{kb}}$ : & $\begin{array}{l}\text { Transmission rate of communication link } \\
\text { (or path) } l_{\mathrm{kb}}\end{array}$ \\
\hline$d_{\mathrm{kb}}:$ & Distance between two processor $\mathrm{p}_{\mathrm{k}}$ and $\mathrm{p}_{\mathrm{b}}$ \\
\hline $\operatorname{IPDM}=\left[\mathrm{d}_{\mathrm{kb}}\right]$ & Inter processor distance matrix \\
\hline
\end{tabular}

\subsection{System Costs:}

The fuzzy execution time $\tilde{e}_{i, j}$ is the amount of the work to be performed by the executing task $t_{i}$ on the processor $p_{j}$. For an allocation $\mathrm{A}$, the overall fuzzy execution time and fuzzy execution time for each processor are calculated by using equations (1) and (2) respectively as:

$$
\begin{gathered}
\operatorname{FET}(A)=\sum_{1 \leq i \leq m} \mathbb{E}_{i, A(i)}, \\
\operatorname{PFET}(A)_{j}=\sum_{\substack{1 \leq i \leq m \\
i \in T S_{j}}} \mathcal{E}_{i, A(i)},
\end{gathered}
$$

where $\operatorname{TS}_{\mathrm{j}}=\{\mathrm{i}: \mathrm{A}(\mathrm{i})=\mathrm{j}, \quad \mathrm{j}=1,2 \ldots \mathrm{n}\}$

The fuzzy inter task communication time $\tilde{c}_{i, j}$ is incurred due to the data units exchanged between the tasks $t_{i}$ and $t_{j}$ if they are on different processors during the process of execution. Let us denote $d_{x, y}$ the distance between the processors $P_{x}$ and $\mathrm{P}_{\mathrm{y}}$. The processors $\mathrm{P}_{\mathrm{x}}$ and $\mathrm{P}_{\mathrm{y}}$ are connected by a communication link say $l_{\mathrm{x}, \mathrm{y}}$. The inter-processor communication cost per unit of information transferred between two processors $\mathrm{P}_{\mathrm{x}}$ and $\mathrm{P}_{\mathrm{y}}$ increases linearly as the distances $d_{x, y}$ increases. To consider the impact of inter processor distance on the cost, we define a inter processor distance matrix IPDM $=\left[\mathrm{d}_{\mathrm{x}, \mathrm{y}}\right]$. Thus, if two interacting tasks $t_{i}$ and $t_{j}$ are assigned to two different processors $P_{k}$ and $\mathrm{P}_{\mathrm{s}}$ respectively, then the two tasks cause the inter-processor communication cost of $\tilde{c}_{i, j} * \mathrm{~d}_{\mathrm{k} . \mathrm{s}}$.We assume that the communication cost between two tasks assigned to the same processors is negligible, since all communication is through memory as opposed to an inter-processor link.

For an allocation A, the overall fuzzy inter-task communication times and fuzzy inter-task communication times for each processor are calculated by using equations (3) and (4) respectively as

$$
\begin{gathered}
\operatorname{FITCT}(A)=\sum_{\substack{1 \leq i \leq m \\
I+1 \leq j \leq M \\
A(i) \neq A(j)}} \tilde{c}_{A(i), A(j)} * d_{A(i), A(j)} \\
\operatorname{PFITCT}(A)_{j}=\sum_{\substack{1 \leq i \leq m \\
i+1 \leq j \leq m \\
A(i)=j \neq A(k)}} \tilde{c}_{A(i), A(k)}
\end{gathered}
$$

The total cost, TCOST (A) of the system for an allocation A is computed as:

$$
\operatorname{TCOST}(\mathrm{A})=\text { FET }(\mathrm{A})+\mathrm{FITCT}(\mathrm{A})
$$

The response time (RT) is a function of the amount of computation to be performed by each processor and the communication time. This function is defined by considering the processor with the heaviest aggregate computation and communication loads of the processors. The fuzzy response time of the system for the allocation is defined as:

$$
R T(A)=\max _{1 \leq I \leq n}\left\{\operatorname{PFET}(A)_{j}+\operatorname{PFITCT}(A)_{j}\right\}
$$

\subsection{Processor Reliability (PR):}

It is the probability that the processor $\mathrm{p}_{\mathrm{k}}$ is operational during the execution of all tasks assigned to $p_{k}$ under a given task allocation. The reliability of system components (i.e., processors and communication links) during a time interval $[0, \mathrm{t}]$ follow the Poisson distribution $\mathrm{R}(\mathrm{t})=\exp \left(\int_{0}^{t} \lambda d t\right)$, and it reduces to $\exp (-\lambda t)$ during the successful mission. The execution reliability of the processor $\mathrm{p}_{\mathrm{k}}$ for executing the tasks assigned to it under the allocation $\mathrm{A}$ is calculated by:

$$
\operatorname{ER}\left(\mathrm{p}_{\mathrm{k}}\right)=\exp \left(-\lambda_{\mathrm{k}} * \operatorname{PFET}(\mathrm{A})_{\mathrm{j}}\right)
$$

where $\lambda_{k}$ is failure rate of the $\mathrm{k}$-th processor $\mathrm{P}_{\mathrm{k}}$.

\subsection{Communication Links Reliability (CLR):}

Communication links reliability is the probability that the communication link or path (i.e., the link or path between two different processors $\mathrm{p}_{\mathrm{k}}$ and $\mathrm{p}_{\mathrm{b}}$ ) is operational for communicating the data between tasks $t_{i}$ and $t_{j}$ that are residing at separate processors. The CLR for a processor $p_{k}$, during an assignment $\mathrm{A}$ incurred due to the FITCT is calculated by: 


$$
\operatorname{CLR}\left(\mathrm{P}_{\mathrm{k}}\right)=\prod_{j=1}^{m} \exp \left[-\mu_{\mathrm{k}, \mathrm{A}(\mathrm{j})} * \sum_{\substack{1 \leq \mathrm{i} \leq \mathrm{m} \\ \mathrm{A}(\mathrm{i})=\mathrm{k} \neq \mathrm{A}(\mathrm{j})}} \mathrm{c}_{\mathrm{i}, \mathrm{j}} * \mathrm{~d}_{\mathrm{k}, \mathrm{A}(\mathrm{j})}\right]
$$

where $\mu_{k, A(j)}$ is failure rate of link $l_{k, A(j)}$

The total communication reliability for $\mathrm{k}$-th processor is the product of execution reliability and communication link reliability associated with processor $\mathrm{P}_{\mathrm{k}}$ for an allocation $\mathrm{A}$ and calculated as:

$\operatorname{TCR}\left(\mathrm{p}_{\mathrm{k}}\right)=\mathrm{ER}\left(\mathrm{p}_{\mathrm{k}}\right) * \operatorname{CLR}\left(\mathrm{p}_{\mathrm{k}}\right)$

The system reliability (SR) wherein all involved system components are operational during the mission is computed as follows:

$$
\mathrm{SR}=\prod_{k=1}^{n} T C R\left(\mathrm{p}_{\mathrm{k}}\right)
$$

\subsection{Assumptions:}

$\left(\mathbf{A}_{1}\right)$. The state of the components of DRTS (i.e., processors and communication links) is either operational or failed. Further, it is also assumed that the failures of components are statistically independent.

$\left(\mathbf{A}_{2}\right)$. A task of a program will execute on a particular processor only when it satisfies a constraint imposed on that processor, otherwise the task moves towards the next processor for getting execution.

$\left(\mathbf{A}_{3}\right)$. A task may take different fuzzy execution time if it executes on different processors and an amount of data may take different fuzzy communication time if it is transmitted through the different communication links. Therefore, the system cost and system reliability, both depend upon the execution and communication time.

$\left(\mathbf{A}_{4}\right)$. Once the tasks are allocated to the processors, they reside on those processors until the execution of the program is completed. Whenever a group of tasks is assigned to the same processor, the FITCT between them is zero.

\section{PROPOSED METHOD}

In this section, a heuristic tasks allocation model is proposed for solving a load balancing tasks allocation problem. The model addressed in this paper is completed in the following major steps:

Step 1: Inputs: Inputs are as:

(a): A program of $m$ tasks $\left\{\mathrm{t}_{1}, \mathrm{t}_{2} \ldots . \mathrm{t}_{\mathrm{m}}\right\}$.

(b): A set $P=\left\{p_{1}, p_{2}, \ldots . p_{n}\right\}$ of $n$ processors.

(c): Fuzzy execution times $\tilde{e}_{i, j}$ and fuzzy inter tasks communication times $\tilde{c}_{i, j}$ which are either in triangular or trapezoidal or Bell shaped or Gaussian types of membership function form. Write Fuzzy execution times $\tilde{e}_{i, j}$ and fuzzy inter tasks communication times $\tilde{c}_{i, j}$ these times are given in the form of matrices $\left[\mathcal{E}_{i, j}\right]$ and $\left[\mathcal{E}_{i, j}\right]$ respectively.

(d): $\operatorname{IPDM}=\left[\mathrm{d}_{\mathrm{kb}}\right], \quad \mathrm{CPFRM}=\left[\mu_{\mathrm{kb}}\right], \quad \mathrm{k}=1,2,3 \ldots \mathrm{n}$, $\mathrm{b}=1,2,3 \ldots . . \mathrm{n}$.

Step 2: Defuzzification: The input times $\tilde{e}_{i, j}$ and $\tilde{c}_{i, j}$ are converted into crisp ones. This step is called defuzzified. In the present paper, we are using the following methods for defuzzification:

(a) Center of Area: In the Center of Area (CoA) defuzzification method, we first calculates the area under the scaled membership functions and within the range of the output variable, then we uses the following equation to calculate the geometric center of this area.

$$
e_{i j}\left(\text { or } c_{i j}\right)=\frac{\int_{x \min }^{x \max } f(x) \cdot x d x}{\int_{x \min }^{x \max } f(x) d x}
$$

where $\mathrm{CoA}$ is the center of area, $x$ is the value of the linguistic variable, and $x_{\min }$ and $x_{\max }$ represent the range of the linguistic variable. The following figure illustrates the CoA defuzzification method:

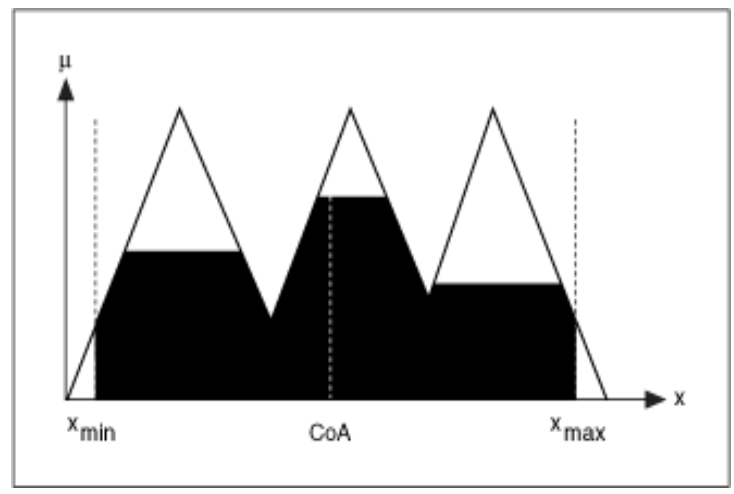

In the figure, $\mu$ is the degree of membership, and the shaded portion of the graph represents the area under the scaled membership functions.

(b) Robust's Ranking Method: If $\left(a_{\alpha}^{L}, a_{\alpha}^{U}\right)$ is a $\alpha$ - cut for a fuzzy number (either $\tilde{e}_{i, j}$ or $\tilde{c}_{i, j}$ ) then its corresponding defuzzified crips value is calculated by the following equation as:

$$
\begin{gathered}
e_{i j}=R\left(\tilde{e}_{i, j}\right)=\frac{1}{2} \int_{0}^{1}\left(a_{\alpha}^{L}+a_{\alpha}^{U}\right) d \alpha \\
c_{i j}=R\left(\tilde{c}_{i, j}\right)=\frac{1}{2} \int_{0}^{1}\left(a_{\alpha}^{L}+a_{\alpha}^{U}\right) d \alpha
\end{gathered}
$$

(c) Center of Maximum: In the Center of Maximum (CoM) defuzzification method, we first determines the typical numerical value for each scaled membership function, as the following figure illustrates. The typical numerical value is the mean of the numerical values corresponding to the degree of membership at which the membership function was scaled.

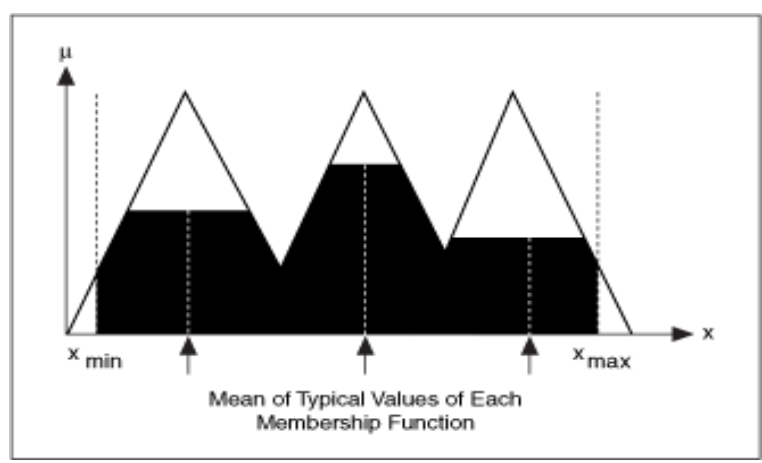

Then we use the following equation to calculate a weighted average of the typical values of a fuzzy number (either $\tilde{e}_{i, j}$ or $\left.\tilde{c}_{i, j}\right)$ : 


$$
e_{i j}\left(\text { or } c_{i j}\right)=\frac{x_{1} \mu_{1}+x_{2} \mu_{2}+\cdots x_{n} \mu_{n}}{\mu_{1}+\mu_{2}+\cdots \mu_{n}}
$$

where $x_{\mathrm{n}}$ is the typical numerical value for the scaled membership function $n$ and $\mu_{\mathrm{n}}$ is the degree of membership at which membership function $n$ was scaled

(d) Mean of Maximum: In the Mean of Maximum (MoM) defuzzification method, we first identify the scaled membership function with the greatest degree of membership, then we determines the typical numerical value for that membership function. The typical numerical value is the mean of the numerical values corresponding to the degree of membership at which the membership function was scaled. The following figure illustrates the MoM defuzzification method.

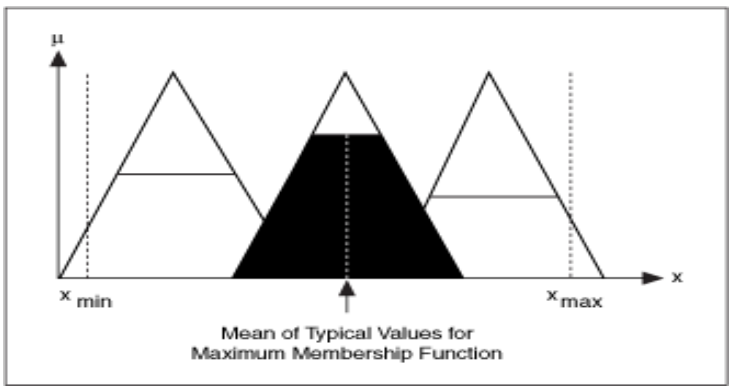

Defuzzified fuzzy execution times $\tilde{e}_{i, j}$ and fuzzy inter tasks communication times $\tilde{c}_{i, j}$ are stored in the form of matrices $\left[e_{i, j}\right]$ and $\left[c_{i, j}\right]$ respectively.

Step 3: Task selection order: Since the numbers of the tasks are more than number of processors, therefore the priority for their execution to be set based on their execution and communication costs. The tasks selection list, $\mathrm{T}_{\text {non-asg }}\{\}$ is generated by sorting the tasks with respect to increasing order of their cost function $\mathrm{CF}\left(\mathrm{t}_{\mathrm{i}}\right)$ that are calculated as:

$$
\underset{1 \leq i \approx m}{C F\left(t_{i}\right)}=\frac{\sum_{j=1}^{n} e_{i j}}{n}+\max _{1 \leq j \approx m}\left\{c_{i j}\right\}
$$

Tie -breaking is done randomly; i.e. one of the tasks with equal cost ratio is selected at random. There can be alternative policies for tie-breaking such as select the task whose overall communication cost with the other tasks is minimum. In this paper, we take the linear array $\operatorname{Tasg}\{\}=\left\{\left(\mathrm{t}_{\mathrm{i}}, \mathrm{p}_{\mathrm{j}}\right): \mathrm{t}_{\mathrm{i}} \in \mathrm{T}, \mathrm{p}_{\mathrm{j}} \in \mathrm{P}\right\}$ to store the assigned tasks those get assigned to the processors. Initially, we assume that the linear arrays $\mathrm{T}_{\text {asg }}\{\}$ is empty.

Step 4: Assignment of the tasks to the processors: In order to make best use of the resources, it becomes essential to maximize the overall throughput by allocating the tasks to processors in such a way that the allocated load on all the processors should be balanced and to minimize the inter tasks communication by assigning tasks to same processor as much as possible. Which are both contrary to each other as an increase in the number of processors may actually decrease the total throughput of the system. This degradation effect is known as saturation effect, which occurs due to heavy communication traffic induced by data transfers between tasks that reside on separate processors. For balancing the load on each processor, we restrict the number of tasks on a processor by:

Maximum number NT (j), of tasks assigned on the $\mathrm{j}^{\text {th }}$ processor $\leq\lceil\mathrm{m} / \mathrm{n}\rceil$
The detailed process of allocating the task to the processors is given below in the form of algorithm.

\section{Algorithm:}
1. Inputs: $\quad \mathrm{FETM}=\left[\varepsilon_{i, j}\right], \quad \operatorname{FITCTM}=\left[\varepsilon_{i, j}\right] \quad$, $\mathrm{i}=1,2,3 \ldots \mathrm{m} \quad, \quad \mathrm{j}=1,2,3 \ldots . . \mathrm{n}, \quad \mathrm{IPDM}=\left[\mathrm{d}_{\mathrm{k}, \mathrm{b}}\right]$, CLFRM $=\left[\mu_{k, b}\right], k=i=1,2,3 \ldots n, b=i=1,2,3 \ldots n$.

2. Initialize:

$$
\begin{aligned}
& \mathrm{T}_{\text {non-ass }}\{\} \leftarrow \Phi \\
& \mathrm{T}_{\text {asg }}\{\} \leftarrow \Phi \\
& \mathrm{NT}(\mathrm{j})\} \leftarrow 0 \text { for } j \leftarrow 1 \text { to } \mathrm{n}
\end{aligned}
$$

3. (a)Defuzzify $\tilde{e}_{i, j}$ and $\tilde{c}_{i, j}$ into crisp values $e_{i, j}$ and $c_{i, j}$ respectively using any one of the method defined in step 2.

(b) Store crisp values $e_{i, j}$ and $c_{i, j}$ in the form of matrices $\left[e_{i, j}\right]$ and $\left[c_{i, j}\right]$ respectively.

4. for $i \leftarrow 1$ to $\mathrm{m}$

Compute:

$\mathrm{CF}\left(\mathrm{t}_{\mathrm{i}}\right)$

5. for $i \leftarrow 1$ to $m$

Sort the tasks in a linear array $\mathrm{T}_{\text {non-ass }}\{\}$ by increasing order of their $\mathrm{CF}\left(\mathrm{t}_{\mathrm{i}}\right)$ values.

6. While $T_{\text {non-ass }}\{\} \neq \phi$ do

begin

Pick-up the first task say $\mathrm{t}_{\mathrm{u}}$ from $\mathrm{T}_{\text {non-ass }}\{\}$.

6.1 Find $\min \left\{\mathrm{e}_{\mathrm{u}, \mathrm{j}}\right\}$ from $\left[e_{i, j}\right]$ for $\mathrm{j} \leftarrow 1$ to $\mathrm{n}$

if

$$
\min \left\{e_{u, j}\right\} \text { is for } j=r
$$

and

$$
\mathrm{NT}(\mathrm{r})+1 \leq\lceil\mathrm{m} / \mathrm{n}\rceil
$$

then

(a) Assign the task $t_{u}$ to processor $p_{r}$

(b) NT (r) $\leftarrow \mathrm{NT}(\mathrm{r})+1$

(c) $\mathrm{T}_{\text {non-ass }}\{\} \leftarrow \mathrm{T}_{\text {non-ass }}\{\} /\left\{\mathrm{t}_{\mathrm{u}}\right\}$

(d) $\mathrm{T}_{\text {asg }}\{\} \leftarrow \mathrm{T}_{\text {asg }}\{\} \cup\left\{\mathrm{t}_{\mathrm{u}}\right\}$

else

go to step 6.2.

6.2 Find the $\min \left\{\mathrm{e}_{\mathrm{u}, \mathrm{j}}\right\}$ from $\left[e_{i, j}\right]$ for $\mathrm{j} \leftarrow 1$ to $\mathrm{n}(j \neq r)$

if

$$
\min \left\{\mathrm{e}_{\mathrm{u}, \mathrm{j}}\right\} \text { is for } \mathrm{j}=\mathrm{k}(j \neq r)
$$

and

$$
\mathrm{NT}(\mathrm{k})+1 \leq\lceil\mathrm{m} / \mathrm{n}\rceil
$$

then

(a) Assign the task $\mathrm{t}_{\mathrm{u}}$ to processor $\mathrm{p}_{\mathrm{k}}$ 


$$
\begin{aligned}
& \text { (b) } \mathrm{NT}(\mathrm{k}) \leftarrow \mathrm{NT}(\mathrm{k})+1 \\
& \text { (c) } \mathrm{T}_{\text {non-ass }}\{\} \leftarrow \mathrm{T}_{\text {non-ass }}\{\} /\left\{\mathrm{t}_{\mathrm{u}}\right\} \\
& \text { (d) } \mathrm{T}_{\text {asg }}\{\} \leftarrow \mathrm{T}_{\text {asg }}\{\} \cup\left\{\mathrm{t}_{\mathrm{u}}\right\}
\end{aligned}
$$

else

$$
\text { repeat the step 6.2. }
$$

7. end while.

8. Make the same assignment of the tasks into the original of matrix $\left[\tilde{\mathrm{e}}_{\mathrm{i}, \mathrm{j}}\right]$.

9. Compute:

$$
\begin{aligned}
& \operatorname{PFET}(A)_{j}=\sum_{\substack{1 \leq i \leq m \\
i \in T S_{j}}} \varepsilon_{i, A(i)} \\
& \operatorname{PFITCT}(A)_{j}=\sum_{\substack{1 \leq i \leq m \\
i+1 \leq j \leq m \\
A(i)=j \neq A(k)}} \tilde{c}_{A(i), A(k)} \\
& \operatorname{TCOST}(\mathrm{A})=\operatorname{FET}(\mathrm{A})+\operatorname{FITCT}(\mathrm{A}) \\
& \operatorname{TCR}\left(\mathrm{p}_{\mathrm{k}}\right)=\operatorname{ER}\left(\mathrm{p}_{\mathrm{k}}\right) * \operatorname{CLR}\left(\mathrm{p}_{\mathrm{k}}\right) \\
& \operatorname{SR}=\prod_{k=1}^{n} \operatorname{TCR}\left(\mathrm{p}_{\mathrm{k}}\right)
\end{aligned}
$$

10. End.

\section{EXPERIMENTAL RESULTS}

The method for allocating the tasks to the processors and its algorithm was discussed in the previous section. To evaluate our proposed model we, use a different size of problem in this sectionTwo examples have been illustrated below using the above method.

Example1: We consider a fuzzy DRTS consisting a set $\mathrm{T}=\{\mathrm{t} 1, \mathrm{t} 2, \mathrm{t} 3, \ldots \ldots \mathrm{t} 7\}$ of seven tasks to be executed on four processors $\{\mathrm{p} 1, \mathrm{p} 2, \mathrm{p} 3, \mathrm{p} 4\}$. The failure rates of the processors $\mathrm{p} 1, \mathrm{p} 2, \mathrm{p} 3$ and $\mathrm{p} 4$ are $0.0002,0.0001,0.0003$, and 0.0002 respectively. The execution time of each task on processors has been taken in the form of matrix FETM $=\left[\tilde{e}_{i, j}\right]$ of order $\mathrm{m} \times \mathrm{n}$ whose elements are fuzzy triangular numbers as given in Table 1. Inter tasks communication time between the tasks has been taken in the form of matrix FITCTM $=\left[\tilde{c}_{i, j}\right]$ of order $\mathrm{m}$ whose elements are also fuzzy triangular numbers as given in Table 2. Here we assume that all the communication links have the same transmission rate "wkb" and the execution cost of all the processors per unit time in DCS is unity. The distances between each pair of processors and failure rates communication links have been given in the form of matrices as given in Table 3 and Table 4 respectively.
Table 1: Fuzzy Execution Time Matrix

\begin{tabular}{ccccc}
\hline & $\mathrm{P}_{1}$ & $\mathrm{P}_{2}$ & $\mathrm{P}_{3}$ & $\mathrm{P}_{4}$ \\
\hline $\mathrm{t}_{1}$ & $(0,3,5)$ & $(4,10,12)$ & $(3,7,15)$ & $(8,10,12)$ \\
$\mathrm{t}_{2}$ & $(6,10,13)$ & $(0,2,4)$ & $(4,8,11)$ & $(3,5,7)$ \\
$\mathrm{t}_{3}$ & $(6,9,12)$ & $(10,14,16)$ & $(2,6,8)$ & $(1,3,5)$ \\
$\mathrm{t}_{4}$ & $(10,14,18)$ & $(1,5,7)$ & $(8,11,13)$ & $(0,4,6)$ \\
$\mathrm{t}_{5}$ & $(1,4,6)$ & $(2,8,10)$ & $(4,7,10)$ & $(2,6,9)$ \\
$\mathrm{t}_{6}$ & $(14,17,20)$ & $(0,2,5)$ & $(3,6,8)$ & $(6,9,12)$ \\
$\mathrm{t}_{7}$ & $(15,20,25)$ & $(6,10,14)$ & $(8,10,12)$ & $(1,4,6)$ \\
\hline
\end{tabular}

Table 3: Inter Processor Distance Matrix

\begin{tabular}{ccccc}
\hline & $\mathrm{P}_{1}$ & $\mathrm{P}_{2}$ & $\mathrm{P}_{3}$ & $\mathrm{P}_{4}$ \\
\hline $\mathrm{P}_{1}$ & 0 & 0.8 & 1.2 & 1.5 \\
$\mathrm{P}_{2}$ & 0.8 & 0 & 0.4 & 0.7 \\
$\mathrm{P}_{3}$ & 1.2 & 0.4 & 0 & 0.3 \\
$\mathrm{P}_{4}$ & 1.5 & 0.7 & 0.3 & 0 \\
\hline
\end{tabular}

Table 4: Communication Link Failure Rate Matrix

\begin{tabular}{ccccc}
\hline & $\mathrm{P}_{1}$ & $\mathrm{P}_{2}$ & $\mathrm{P}_{3}$ & $\mathrm{P}_{4}$ \\
\hline $\mathrm{P}_{1}$ & ------- & 0.0003 & 0.0004 & 0.0005 \\
$\mathrm{P}_{2}$ & 0.0003 & ------ & 0.0001 & 0.0001 \\
$\mathrm{P}_{3}$ & 0.0004 & 0.0001 & ------ & 0.0001 \\
$\mathrm{P}_{4}$ & 0.0005 & 0.0002 & 0.0001 & ------ \\
\hline
\end{tabular}

Tables-5 and 6 are showing the optimal costs and optimal reliability of the system for optimal assignment of tasks to the processors. The times have been defuzzified into crisp one by using Robust Ranking Method [RRM], Centre of Maxima Method [CoM] and Center of Area Method [CoA]. The optimal system cost on applying the Robust Ranking Method [RRM], Centre of Maxima Method [CoM] and Center of Area Method [CoA] are $(105.1,163.8,223),(115.3,178.2,237.2)$ and $(115.3,178.2,237.2)$ respectively. The optimal system reliability on applying the Robust Ranking Method [RRM], Centre of Maxima Method [CoM] and Center of Area Method [CoA] are $(0.89902,0.90055,0.94720)$, $(0.85650,0.90792,0.93585)$ and $(0.85650,0.90792,0.93585)$ respectively.

Table 2: Fuzzy Inter Task Communication Time Matrix

\begin{tabular}{cccccccc}
\hline & $\mathrm{t}_{1}$ & $\mathrm{t}_{2}$ & $\mathrm{t}_{3}$ & $\mathrm{t}_{4}$ & $\mathrm{t}_{5}$ & $\mathrm{t}_{6}$ & $\mathrm{t}_{7}$ \\
\hline $\mathrm{t}_{1}$ & $(0,0,0)$ & $(4,6,8)$ & $(10,13,16)$ & $(0,2,4)$ & $(6,8,10)$ & $(1,3,5)$ & $(2,4,6)$ \\
$\mathrm{t}_{2}$ & $(4,6,8)$ & $(0,0,0)$ & $(15,20,24)$ & $(2,4,6)$ & $(10,12,14)$ & $(1,3,5)$ & $(10,12,16)$ \\
$\mathrm{t}_{3}$ & $(10,13,16)$ & $(15,20,24)$ & $(0,0,0)$ & $(3,5,7)$ & $(10,12,14)$ & $(6,8,10)$ & $(0,2,4)$ \\
$\mathrm{t}_{4}$ & $(0,2,4)$ & $(2,4,6)$ & $(3,5,7)$ & $(0,0,0)$ & $(6,10,16)$ & $(4,6,8)$ & $(20,25,30)$ \\
$\mathrm{t}_{5}$ & $(6,8,10)$ & $(10,12,14)$ & $(10,12,14)$ & $(6,10,16)$ & $(0,0,0)$ & $(0,4,6)$ & $(10,12,16)$ \\
$\mathrm{t}_{6}$ & $(1,3,5)$ & $(1,3,5)$ & $(6,8,10)$ & $(4,6,8)$ & $(0,4,6)$ & $(0,0,0)$ & $(2,4,6)$ \\
$\mathrm{t}_{7}$ & $(2,4,6)$ & $(10,12,16)$ & $(0,2,4)$ & $(20,25,30)$ & $(10,12,16)$ & $(2,4,6)$ & $(0,0,0)$ \\
\hline
\end{tabular}


Table 5: Optimal Costs of the System

\begin{tabular}{|c|c|c|c|c|c|c|}
\hline \multirow[t]{2}{*}{$\begin{array}{l}\text { Defuzzification } \\
\text { Method }\end{array}$} & \multirow{2}{*}{$\begin{array}{c}\text { Tasks } \\
(1)\end{array}$} & \multirow{2}{*}{$\begin{array}{c}\text { Processors } \\
(2)\end{array}$} & \multicolumn{3}{|c|}{$\begin{array}{c}\text { Processor's cost } \\
\text { (3) }\end{array}$} & \multirow[t]{2}{*}{$R T(A)$} \\
\hline & & & $\begin{array}{l}\text { EC } \\
\text { (a) }\end{array}$ & $\begin{array}{l}\text { IPCC } \\
\text { (b) }\end{array}$ & $(a+b)$ & \\
\hline \multirow{4}{*}{$\begin{array}{l}\text { Robust Ranking } \\
\text { Method[RRM] }\end{array}$} & $\mathrm{t}_{1}, \mathrm{t}_{5}$ & $\mathrm{P}_{1}$ & $(1,7,11)$ & $(65.4,94.7,127.8)$ & $(66.4,111.7,138.8)$ & \multirow{4}{*}{$(105.1,163.8,223)$} \\
\hline & $t_{2}, t_{6}$ & $\mathrm{P}_{2}$ & $(0,4,9)$ & $(35.7,53,68.8)$ & $(35.7,57,77.8)$ & \\
\hline & $\mathrm{t}_{7}$ & $\mathrm{P}_{3}$ & $(8,10,12)$ & $(25.2,33.7,45.4)$ & $(33.2,43.7,57.4)$ & \\
\hline & $\mathrm{t}_{3}, \mathrm{t}_{4}$ & $\mathrm{P}_{4}$ & $(1,7,11)$ & $(63.9,90.2,118.8)$ & $(64.9,97.2,129.8)$ & \\
\hline \multirow{4}{*}{$\begin{array}{l}\text { Center of Area } \\
\text { Method }[\mathrm{CoA}]\end{array}$} & $\mathrm{t}_{1}, \mathrm{t}_{5}$ & $\mathrm{P}_{1}$ & $(6,13,18)$ & $(69.3,8.5,128.6)$ & $(75.3,111.5,146.6)$ & \multirow{4}{*}{$(115.3,178.2,237.2)$} \\
\hline & $\mathrm{t}_{2}, \mathrm{t}_{6}$ & $\mathrm{P}_{2}$ & $(2,10,15)$ & $(115.3,178.2,237.2)$ & $(39.4,62.4,84.6)$ & \\
\hline & $\mathrm{t}_{7}$ & $\mathrm{P}_{3}$ & $(8,10,12)$ & $(25.2,33.7,45.4)$ & $(33.2,43.7,57.4)$ & \\
\hline & $\mathrm{t}_{3}, \mathrm{t}_{4}$ & $\mathrm{P}_{4}$ & $(1,7,11)$ & $(64.7,91.8,118.8)$ & $(65.7,98.8,129.8)$ & \\
\hline \multirow{4}{*}{$\begin{array}{c}\text { Centre of } \\
\text { Maxima } \\
\text { Method }[\mathrm{CoM}]\end{array}$} & $\mathrm{t}_{1}, \mathrm{t}_{2}$ & $\mathrm{P}_{1}$ & $(6,13,18)$ & $(69.3,98.5,128.6)$ & $(75.3,111.5,146.6)$ & \multirow{4}{*}{$(115.3,178.2,237.2)$} \\
\hline & $\mathrm{t}_{5}, \mathrm{t}_{6}$ & $\mathrm{P}_{2}$ & $(2,10,15)$ & $(115.3,178.2,237.2)$ & $(39.4,62.4,84.6)$ & \\
\hline & $t_{7}$ & $\mathrm{P}_{3}$ & $(8,10,12)$ & $(25.2,33.7,45.4)$ & $(33.2,43.7,57.4)$ & \\
\hline & $\mathrm{t}_{3}, \mathrm{t}_{4}$ & $\mathrm{P}_{4}$ & $(1,7,11)$ & $(64.7,91.8,118.8)$ & $(65.7,98.8,129.8)$ & \\
\hline
\end{tabular}

Table-6 Optimal Reliability of the System

\begin{tabular}{|c|c|c|c|c|}
\hline $\begin{array}{l}\text { Defuzzification } \\
\text { Method }\end{array}$ & Tasks & Processors & Processor's Reliability & System Reliability(SR) \\
\hline & (1) & (2) & (3) & \\
\hline \multirow{4}{*}{$\begin{array}{l}\text { Robust Ranking } \\
\text { Method[RRM] }\end{array}$} & $t_{1}, t_{5}$ & $\mathrm{P}_{1}$ & $(0.97565,0.95786,0.97142)$ & \multirow{4}{*}{$(0.89902,0.90055,0.94720)$} \\
\hline & $t_{2}, t_{6}$ & $\mathrm{P}_{2}$ & $(0.97765,0.98305,0.98896)$ & \\
\hline & $\mathrm{t}_{7}$ & $\mathrm{P}_{3}$ & $(0.98216,0.98639,0.98965)$ & \\
\hline & $t_{3}, t_{4}$ & $\mathrm{P}_{4}$ & $(0.95964,0.96957,0.97893)$ & \\
\hline \multirow{4}{*}{$\begin{array}{l}\text { Center of Area } \\
\text { Method [CoA] }\end{array}$} & $\mathrm{t}_{1}, \mathrm{t}_{5}$ & $\mathrm{P}_{1}$ & $(0.92682,0.96435,0.97590)$ & \multirow{4}{*}{$(0.85650,0.90792,0.93585)$} \\
\hline & $t_{2}, t_{6}$ & $\mathrm{P}_{2}$ & $(0.97951,0.98432,0.98985)$ & \\
\hline & $t_{7}$ & $\mathrm{P}_{3}$ & $(0.98216,0.98639,0.98926)$ & \\
\hline & $\mathrm{t}_{3}, \mathrm{t}_{4}$ & $\mathrm{P}_{4}$ & $(0.96060,0.96967,0.97932)$ & \\
\hline \multirow{4}{*}{$\begin{array}{l}\text { Centre of Maxima } \\
\text { Method[CoM }]\end{array}$} & $\mathrm{t}_{1}, \mathrm{t}_{2}$ & $\mathrm{P}_{1}$ & $(0.92682,0.96435,0.97590)$ & \multirow[t]{4}{*}{$(0.85650,0.90792,0.93585)$} \\
\hline & $t_{5}, t_{6}$ & $\mathrm{P}_{2}$ & $(0.97951,0.98432,0.98985)$ & \\
\hline & $\mathrm{t}_{7}$ & $\mathrm{P}_{3}$ & $(0.98216,0.98639,0.98926)$ & \\
\hline & $\mathrm{t}_{3}, \mathrm{t}_{4}$ & $\mathrm{P}_{4}$ & $(0.96060,0.96967,0.97932)$ & \\
\hline
\end{tabular}

Table 7: Fuzzy Execution Time Matrix

\begin{tabular}{ccccc}
\hline & $\mathrm{P}_{1}$ & $\mathrm{P}_{2}$ & $\mathrm{P}_{3}$ & $\mathrm{P}_{4}$ \\
\hline $\mathrm{t}_{1}$ & $(2,6,9,12)$ & $(4,10,14,18)$ & $(4,12,15,20)$ & $(6,11,17,23)$ \\
$\mathrm{t}_{2}$ & $(0,3,8,12)$ & $(8,16,22,26)$ & $(7,11,15,19)$ & $(7,10,12,15)$ \\
$\mathrm{t}_{3}$ & $(1,5,9,14)$ & $(6,10,15,20)$ & $(6,11,14,20)$ & $(2,10,13,21)$ \\
$\mathrm{t}_{4}$ & $(6,13,20,27)$ & $(3,9,13,19)$ & $(0,5,7,9)$ & $(5,10,15,20)$ \\
$\mathrm{t}_{5}$ & $(5,7,9,11)$ & $(11,15,19,24$ & $(8,12,16,20)$ & $(10,13,16,19)$ \\
$\mathrm{t}_{6}$ & $(2,9,15,20)$ & $(4,8,12,16)$ & $(6,12,18,24)$ & $(5,9,13,17)$ \\
$\mathrm{t}_{7}$ & $(5,11,17,23)$ & $(7,9,12,15)$ & $(12,18,24,30)$ & $(16,21,26,30)$ \\
\hline
\end{tabular}


Table 8: Fuzzy Inter Task Communication Time Matrix

\begin{tabular}{cccccccc}
\hline & $\mathrm{t}_{1}$ & $\mathrm{t}_{2}$ & $\mathrm{t}_{3}$ & $\mathrm{t}_{4}$ & $\mathrm{t}_{5}$ & $\mathrm{t}_{6}$ & $\mathrm{t}_{7}$ \\
\hline $\mathrm{t}_{1}$ & $(0,0,0,0)$ & $(0,2,4,6)$ & $(2,4,5,6)$ & $(1,3,5,6)$ & $(2,3,4,5)$ & $(0,1,2,3)$ & $(3,4,5,6)$ \\
$\mathrm{t}_{2}$ & $(0,2,4,6)$ & $(0,0,0,0)$ & $(1,2,3,4)$ & $(1,2,4,6)$ & $(2,4,5,6)$ & $(1,3,4,5)$ & $(2,3,4,5)$ \\
$\mathrm{t}_{3}$ & $(2,4,5,6)$ & $(1,2,3,4)$ & $(0,0,0,0)$ & $(3,4,6,8)$ & $(0,1,2,3)$ & $(2,3,4,5)$ & $(1,2,3,4)$ \\
$\mathrm{t}_{4}$ & $(1,3,5,6)$ & $(1,2,4,6)$ & $(3,4,6,8)$ & $(0,0,0,0)$ & $(2,4,6,7)$ & $(1,3,4,6)$ & $(2,3,4,5)$ \\
$\mathrm{t}_{5}$ & $(2,3,4,5)$ & $(2,4,5,6)$ & $(0,1,2,3)$ & $(2,4,6,7)$ & $(0,0,0,0)$ & $(2,4,6,8)$ & $(3,5,6,7)$ \\
$\mathrm{t}_{6}$ & $(0,1,2,3)$ & $(1,3,4,5)$ & $(2,3,4,5)$ & $(1,3,4,6)$ & $(2,4,6,8)$ & $(0,0,0,0)$ & $(4,6,8,10)$ \\
$\mathrm{t}_{7}$ & $(3,4,5,6)$ & $(2,3,4,5)$ & $(1,2,3,4)$ & $(2,3,4,5)$ & $(3,5,6,7)$ & $(4,6,8,10)$ & $(0,0,0,0)$ \\
\hline
\end{tabular}

Table 9: Optimal Costs of the System

\begin{tabular}{|c|c|c|c|c|c|c|}
\hline \multirow[t]{2}{*}{$\begin{array}{c}\text { Defuzzification } \\
\text { Method }\end{array}$} & \multirow{2}{*}{$\begin{array}{c}\text { Tasks } \\
(1)\end{array}$} & \multirow{2}{*}{$\begin{array}{c}\text { Processors } \\
(2)\end{array}$} & \multicolumn{3}{|c|}{$\begin{array}{c}\text { Processor's cost } \\
\text { (3) }\end{array}$} & \multirow[t]{2}{*}{$R T(A)$} \\
\hline & & & $\begin{array}{l}\text { EC } \\
\text { (a) }\end{array}$ & $\begin{array}{l}\text { IPCC } \\
\text { (b) }\end{array}$ & $(a+b)$ & \\
\hline \multirow{4}{*}{$\begin{array}{l}\text { Robust Ranking } \\
\text { Method[RRM] }\end{array}$} & $\mathrm{t}_{1}, \mathrm{t}_{2}$ & P1 & $(2,9,17,24)$ & $(17.2,35,49.8,63.4)$ & $(19.2,44,66.8,87.4)$ & \multirow{4}{*}{$(48.5,101.4,144.9,197.5)$} \\
\hline & $\mathrm{t}_{7}$ & $\mathrm{P} 2$ & $(7,9,12,15)$ & $(9.5,14.3,18.9,23.4)$ & $(16.5,23.3,30.9,38.4)$ & \\
\hline & $t_{4}, t_{5}$ & P3 & $(8,17,23,29)$ & $(11,21.2,31,39.9)$ & $(19,38.2,54,68.9)$ & \\
\hline & $\mathrm{t}_{3}, \mathrm{t}_{6}$ & P4 & $(7,19,26,44)$ & $(11.3,24.2,35.1,44.3)$ & $(18.3,43.2,61.1,88.3)$ & \\
\hline \multirow{4}{*}{$\begin{array}{l}\text { Center of Area } \\
\text { Method }[\mathrm{CoA}]\end{array}$} & $\mathrm{t}_{1}, \mathrm{t}_{3}$ & P1 & $(3,11,18,26)$ & $(15.2,30,46,60.8)$ & $(18.2,41,64,86.8)$ & \multirow{4}{*}{$(55.5,102.3,145.7,188.9)$} \\
\hline & $\mathrm{t}_{7}$ & $\mathrm{P} 2$ & $(7,9,12,15)$ & $(9.7,14.9,19.4,23.9)$ & $(16.7,23.9,31.4,38.9)$ & \\
\hline & $\mathrm{t}_{2}, \mathrm{t}_{4}$ & P3 & $(7,16,22,28)$ & $(9.4,19.8,30.5,40)$ & $(16.4,35.8,52.5,68)$ & \\
\hline & $\mathrm{t}_{5}, \mathrm{t}_{6}$ & $\mathrm{P} 4$ & $(15,22,29,36)$ & $(12.7,23.9,33.5,43.1)$ & $(27.7,45.9,62.5,79.1)$ & \\
\hline \multirow{4}{*}{$\begin{array}{c}\text { Centre of } \\
\text { Maxima } \\
\text { Method[CoM] }\end{array}$} & $\mathrm{t}_{1}, \mathrm{t}_{2}$ & P1 & $(2,9,17,24)$ & $(18.3,33.3,45.9,57.7)$ & $(20.3,42.3,62.9,81.7)$ & \multirow{4}{*}{$(66.3,111.7,163.8,213.2)$} \\
\hline & $\mathrm{t}_{4}, \mathrm{t}_{6}$ & $\mathrm{P} 2$ & $(7,17,25,35)$ & $(10.2,19.5,29.2,39.1)$ & $(17.2,36.5,54.2,74.1)$ & \\
\hline & $t_{3}, t_{5}$ & P3 & $(14,23,30,40)$ & $(13.2,23.7,31.9,39.7)$ & $(27.2,46.9,61.9,79.7)$ & \\
\hline & $\mathrm{t}_{7}$ & $\mathrm{P} 4$ & $(16,21,26,30)$ & $(12.9,18.9,24.6,31.7)$ & $(28.9,39.9,50.6,61.7)$ & \\
\hline
\end{tabular}

Table10 Optimal Reliability of the System

\begin{tabular}{|c|c|c|c|c|}
\hline Defuzzification & Tasks & Processors & Processor's Reliability & System Reliability(SR) \\
\hline & (1) & (2) & & \\
\hline \multirow{4}{*}{$\begin{array}{l}\text { Robust Ranking } \\
\text { Method[RRM] }\end{array}$} & $\mathrm{t}_{1}, \mathrm{t}_{2}$ & $\mathrm{P} 1$ & $(.96967,0.97648,0.98393,99273)$ & \multirow[t]{4}{*}{$(0.91916,0.93800,0.95686,0.97833)$} \\
\hline & $\mathrm{t}_{7}$ & P2 & $(0.99124,0.99293,0.99461,0.99631)$ & \\
\hline & $\mathrm{t}_{4}, \mathrm{t}_{5}$ & P3 & $(0.97863,0.98324,0.98817,0.99412)$ & \\
\hline & $\mathrm{t}_{3}, \mathrm{t}_{6}$ & $\mathrm{P} 4$ & $(0.97716,0.98393,0.98946,0.99501)$ & \\
\hline \multirow{4}{*}{$\begin{array}{l}\text { Center of Area } \\
\text { Method [CoA] }\end{array}$} & $\mathrm{t}_{1}, \mathrm{t}_{3}$ & P1 & $(0.97453,0.98098,0.98768,0.99422)$ & \multirow[t]{4}{*}{$(0.92580,0.94233,0.97171,0.98432)$} \\
\hline & $\mathrm{t}_{7}$ & P2 & $(0.99114,0.99283,0.99452,0.99631)$ & \\
\hline & $\mathrm{t}_{2}, \mathrm{t}_{4}$ & P3 & $\begin{array}{c}(0.97883,0.98364,0.98886,0.99491) \\
\end{array}$ & \\
\hline & $\mathrm{t}_{5}, \mathrm{t}_{6}$ & P4 & $(0.97922,0.98364,0.98807,0.99302)$ & \\
\hline \multirow{4}{*}{$\begin{array}{l}\text { Centre of Maxima } \\
\text { Method }[\mathrm{CoM}]\end{array}$} & $\mathrm{t}_{1}, \mathrm{t}_{2}$ & P1 & $\begin{array}{l}(0.97560,0.98098,0.98689,0.99342) \\
\end{array}$ & \multirow[t]{4}{*}{$(0.92247,0.93923,0.95562,0.97443)$} \\
\hline & $\mathrm{t}_{4}, \mathrm{t}_{6}$ & $\mathrm{P} 2$ & $(0.98442,0.98847,0.99233,99631)$ & \\
\hline & $\mathrm{t}_{3}, \mathrm{t}_{5}$ & P3 & $(0.97599,0.98128,0.98580,0.99173)$ & \\
\hline & $\mathrm{t}_{7}$ & P4 & $(0.98413,0.98708,0.98985,0.99273)$ & \\
\hline
\end{tabular}


Example 2: Let us consider a fuzzy DRTS consisting a set $\mathrm{T}=\left\{\mathrm{t}_{1}, \mathrm{t}_{2}, \mathrm{t}_{3}, \ldots \ldots . \mathrm{t}_{7}\right\}$ of " $\mathrm{m}=6$ " executable tasks and a set $\mathrm{P}=$ $\left\{\mathrm{P}_{1}, \mathrm{P}_{2}, \mathrm{P}_{3}, \mathrm{P}_{4}\right\}$ of " $\mathrm{n}=4$ " processors. The failure rates of the processors $\mathrm{p}_{1}, \mathrm{p}_{2}, \mathrm{p}_{3}$ and $\mathrm{p}_{4}$ are $0.0002,0.0001,0.0003$, and 0.0002 respectively. The execution time of each task on processors has been taken in the form of matrix FETM = $\left[\tilde{e}_{i, j}\right]$ of order $\mathrm{m} \times \mathrm{n}$ whose elements are fuzzy trapezoidal numbers as given in Table 7 . Inter tasks communication time between the tasks has been taken in the form of matrix FITCTM $=\left[\tilde{c}_{i, j}\right]$ of order $\mathrm{m}$ whose elements are also fuzzy trapezoidal numbers as given in Table 8 . Here we assume that all the communication links have the same transmission rate " $\mathrm{w}_{\mathrm{kb}}$ " and the execution cost of all the processors per unit time in DCS is unity. The distances between each pair of processors and failure rates communication links have been taken same as taken in example 1 and given in Table 3 and Table 4 respectively.

Tables- 9 and 10 are showing the optimal costs and optimal reliability of the system for optimal assignment of tasks to the processors. The times have been defuzzified into crisp one by using Robust Ranking Method [RRM], Centre of Maxima Method $[\mathrm{CoM}]$ and Center of Area Method [CoA]. The optimal system cost on applying the Robust Ranking Method [RRM], Center of Area Method [CoA] and Centre of Maxima Method [CoM] are $(48.5,101.4,144.9,197.5)$, $(55.5,102.3,145.7,188.9) \quad$ and $(66.3,111.7,163.8,213.2)$ respectively. The optimal system reliability on applying the Robust Ranking Method [RRM], Center of Area Method [CoA] and Centre of Maxima Method [CoM] are $(0.91916,0.93800,0.95686,0.97833),(0.92580,0.94233,0.9717$ $1,0.98432) \quad$ and $\quad(0.92247,0.93923,0.95562,0.97443)$ respectively.

\section{CONCLUSION}

In this paper we have introduce a new fuzzy tasks allocation problem and its solution procedure. The problem has been formulated and depicted by a mathematical model. Fuzzy execution times $\tilde{e}_{i, j}$ and fuzzy inter tasks communication times $\tilde{c}_{i, j}$ has been used while developing the model which are more realistic and general in nature. Several sets of input data are used to test the effectiveness and efficiency of model. It is found that the model is suitable for arbitrary number of processors with the random program structure.

For evaluating the performance of our algorithm a large number of programs were considered. The numbers of tasks in the examples were restricted to ten. These programs were tested for the three cases. In Case-1, Robust ranking, in Case2 centre of maxima method and in Case-3, centre of area method is selected for difuzzification. We present a pair-wise comparison of each case with the other cases. In these comparisons, the percentage that each difuzzification produced better, equal or worse response time of the system is counted for the 300 task programs in the experiments. Table11 shows the comparison results of the algorithm for these three cases. The combined column represents the percentage of the tasks programs in which the algorithm gives a better, equal or worse performance than all other cases combined.

Table-11 Pair-wise comparison of the cases

\begin{tabular}{|l|c|c|c|c|c|}
\hline & & Case 1 & Case 2 & Case 3 & Combined \\
\hline Case 1 & Better & & $80 \%$ & $73 \%$ & $79 \%$ \\
& Equal & - & $11 \%$ & $7 \%$ & $7.5 \%$
\end{tabular}

\begin{tabular}{|c|c|c|c|c|c|}
\hline & \multirow{1}{*}{ Worse } & & $9 \%$ & $20 \%$ & $13.5 \%$ \\
\hline \multirow{3}{*}{ Case2 } & Better & $9 \%$ & & $18 \%$ & $13.5 \%$ \\
& Equal & $11 \%$ & - & $4 \%$ & $7.5 \%$ \\
& Worse & $80 \%$ & & $78 \%$ & $79 \%$ \\
\hline \multirow{2}{*}{ Case 3 } & Better & $20 \%$ & $78 \%$ & & $49 \%$ \\
& Equal & $7 \%$ & $4 \%$ & - & $5.5 \%$ \\
& Worse & $73 \%$ & $18 \%$ & & $45.5 \%$ \\
\hline
\end{tabular}

The ranking of the cases based on the occurrences of the best results is \{case-1, case-3, and case-2\}. These experiment shows that the algorithm for the case- 2 is the best candidate for allocating the tasks to the processors in term of response time of the system. The present model is very useful in telephone networks, cellular network, computer games, image processing, cryptography, industrial process monitoring, simulation of VLSI circuits, sonar and radar surveillance, signal processing, simulation of nuclear reactor, power plants, airplanes, banking system etc.

\section{REFERENCES}

[1] Richard R.Y., Lee E.Y.S. and Tsuchiya M., "A Task Allocation Model for Distributed Computer System", IEEE Trans. on Computer, Vol.C-31 pp.41-47, 1982.

[2] Sinclayer J.B., "Optimal Assignment in Broadcast Network" IEEE Trans. on Computer, Vol.37 (5), pp.521$351,1988$.

[3] Casavent T.L. and Kuhl, J. G., "A Taxonomy of Scheduling in General Purpose Distributed Computing System", IEEE Transactions on Software Engineering, Vol. 14, pp. 141-154, 1988.

[4] Sagar G. and Sarje A.K., "Task Allocation Model for Distributed System”, Int. J. System Science, Vol. 22, pp. 1671-1678, 1991.

[5] Elsade A.A. and Wells B.E. "A Heuristic Model for Task Allocation in Heterogeneous Distributed Computing System", International Journal of Computers and Their Applications, Vol.6 (1), March 1999.

[6] Yadav P.K., Singh M.P. and Sharma K., "Tasks Allocation Model for Reliability and Cost Optimization in Distributed Computing System, International Journal of Modelling, Simulation, and Scientific Computing, Vol. 2, No.2, pp.131-149, 2011.

[7] Singh M.P., Yadav P.K. and Kumar H., Agarwal B., "Dynamic Tasks Scheduling Model for Performance Evaluation of a Distributed Computing System through Artificial Neural Network", Proceedings of the International Conference on Soft Computing for Problem Solving (SocProS 2011) (Advances in Intelligent and Soft Computing: Published by Springer ) Vol.130, pp. 321-331, 2012.

[8] Bokhari, S.H. "Dual Processor Scheduling with Dynamic Re-Assignment”, IEEE Trans. On Software Engineering, Vol.SE-5 pp. 341-349, 1979.

[9] Rotithor H.G., "Taxonomy of Dynamic Task Scheduling in Distributed Computing Systems", IEEE Proc. Computer Digit Tech., Vol. 14, pp. 1-10, 1994. 
[10] Cho S.Y. and Park K.H "Dynamic Task Assignment in Heterogeneous Linear Array Networks for Metacomputing”, Proceeding of IEEE, pp. 66-71, 1994.

[11] Yadav P.K., Singh M.P. and Kumar H., "Scheduling Algorithm: Tasks Scheduling Algorithm for Multiple Processors with Dynamic Reassignment", Journal of Computer Systems, Networks and Communications, Article ID-578180, pp.1-9, 2008.

[12] Donight S.S.and Khanmohammadi S., "A Fuzzy Reliability Model for Series-parallel System”, J. Ind. Eng. Int., Vol. 7, No.12, pp. 10-18, 2011.

[13] Kong X., Lin C., Jiang Y., Yan W. and Chu X., “ Efficient Dynamic Task Scheduling in virtualized Data Center with Fuzzy Prediction", Journal of Network and Computer Applications , Vol.34 , No.4, pp. 1068-1077, 2011.
[14] Kang Q., He H. and Wei J ,"An Effective Iterated Greedy Algorithm for Reliability Oriented Task Allocation in Distributed Computing System", Journal of Parallel and Distributed Computing, Vol. 73, No.8, pp.1106-1115, August 2013.

[15] Kumar H.,. Singh M. P and Yadav P. K, "A Task Allocation Model with Fuzz Execution and Fuzzy Inter Task Communication Times in Distributed Computing System", International Journal of Computer Applications, Vol.72, pp. 24-31, 2013.

[16] Sriramdas V., Chaturvedi S. K. and Gargama H, "Fuzzy Arithmetic Based Reliability Allocation Approach during early Design and Development", Expert System with Application, Vol. 41, No. 7 , pp. 3444-3449, June 2014. 